ing properly. I don't want to change the world, but, at least, to have some little influence and to show that there are some solutions that we have, that are working."

"Waiting times of 9 months, I2 months, to have an MRI is nonsense," he added.

Ouellet was born in Longueuil, Que., earned his medical degree from the University of Montréal in 1970 and a certificate of specialty in diagnostic radiology in 1975 . He served as president of the Québec Medical Association for 2 years beginning in 2005 and is married to Diane Marceau. The couple has 3 children: Maxime, Julie and Sandra. - Wayne Kondro, CMAJ

DOI:I0.1503/cmaj.07I2I9

\section{Physicians go green}

A longer version of this article was published atwww.cmaj.ca on Aug. 23, 2007.

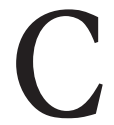
anadian doctors will be asked to become environmental stewards, after $95 \%$ of delegates to the Canadian Medical Association (CMA) General Council voted Aug. 22 to ask physicians to discuss environmental issues with patients, to work with health care facilities to reduce or recycle waste, to make their own work and home environments environmentally friendly and work to include environmental programs in medical education.

The motion on stewardship, put forth by Charlottetown ophthalmologist Gerald O'Hanley, was one of numerous environmental motions that delegates enthusiastically passed at the Vancouver meeting. Solutions to all other problems faced by doctors "will be fruitless if we ignore the health perils posed by global climate change," said O'Hanley in an impassioned plea for support that had the delegates alternately laughing or loudly applauding. "Our message needs to be clear: Canada's physicians, even its conservative, curmudgeonly, cold-steel-on-collagen surgeons like me, who demand high-order evidence to guide life and death decisions, agree with international scientific consensus that it is highly likely mankind is responsible for poisoning the planet to the brink of a febrile convulsion from which many of us and our offspring may not recover."

"We are challenged as a people to dig our head out of the oil sand and face the difficult problems that await," said O'Hanley. "The public expects our leadership in dealing with this overarching issue, and we expect it of ourselves."

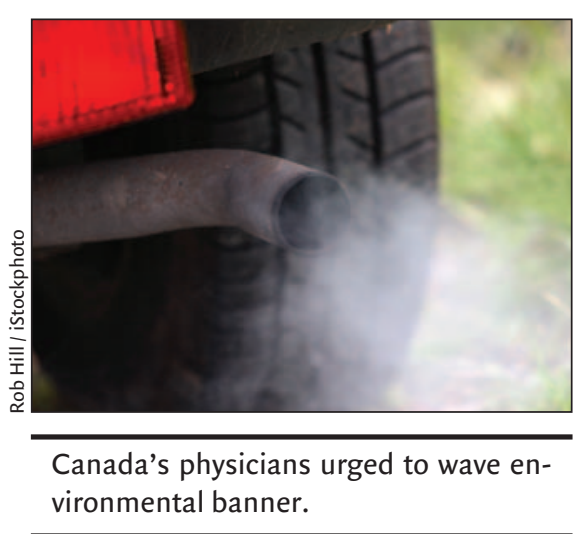

In a session coloured distinctly green, delegates also agreed that the CMA should call for safe drinking water for all Canadians, oppose the cosmetic use of pesticides, take measures to reduce climate change or alleviate its effects, fight air pollution and reduce emissions.

They called on the CMA to lobby the federal government to undertake a national education and prevention campaign about the effect of environmental factors on human health, to start monitoring indoor air pollution and to provide funds to help the health care industry become more environmentally friendly.

Delegates also took aim at the tobacco industry, agreeing to oppose its involvement and sponsorship in education and research at universities, colleges and medical research institutions. They supported motions for a Canadawide ban on smoking in vehicles carrying children and for restoring funding for a federal anti-smoking campaign.

Other motions supported new strategies to reduce emergency department wait times and overcrowding, and calls for the CMA to ask governments to find ways to promote the role of family physi- cians; to revamp the Canada Food Guide; and reduce salt in processed foods.

CMA was also charged with reviewing the availability of and coverage for publicly funded medical services across Canada and acknowledging disparities in publicly insured Canadian medical care. "We have I4 different systems," said Dr. Gregory Flynn of Toronto, who presented both motions, "but I believe all Canadians should have access to the same basket of services."

Delegates also grappled with the pharmaceutical industry, with some 94\% agreeing to ask Ottawa to strengthen laws that ban direct-to-consumer advertising of prescription drugs, thus prohibiting the current "disguised" advertisements that promote drugs without naming them. CMA was also instructed to ask governments to address the high cost of generic and off-patent prescription medicines. A controversial motion, calling on Ottawa to protect the domestic supply of prescription drugs by banning bulk exports to other countries, was defeated.

Delegates also urged adoption of a national physician human resource strategy, further expansion and integration of physician assistants in health care, a comprehensive study of financial and non-financial strategies to retain practising physicians. And they favoured motions to offer clinical electives to Canadian students studying medicine abroad, to institute a national standardized assessment protocol for evaluating international medical graduates, and to develop national, uniform licensure policies for residents.

Council also adopted a motion stating that other health professionals should not be used as physician substitutes. "We want to avoid the situation of multiple providers battling over the same patient without working together," said Dr. John Rapin of Kingston, Ont.

Dr. Bonnie Cham, chair of the CMA's committee on ethics, said that in November, the association will update its policy on conflict of interest between physicians and the pharmaceutical industry, following completion of an ongoing consultation exercise. - Deborah Jones, Vancouver

DOI:I0.I503/cmaj.071220 